\title{
Diversidade e função de fungos micorrízicos arbusculares em sucessão de espécies hospedeiras
}

\author{
Plínio Henrique Oliveira Gomide(1), José Geraldo Donizetti dos Santos(2), José Oswaldo Siqueira(1) \\ e Cláudio Roberto Fonsêca Sousa Soares ${ }^{(1)}$
}

\begin{abstract}
(1)Universidade Federal de Lavras, Departamento de Ciência do Solo, Laboratório de Microbiologia do Solo, Caixa Postal 3037, CEP 37200-000 Lavras, MG. E-mail: pliniogomide@gmail.com, siqueira@ufla.br, crfsoares@gmail.com (2)Universidade Federal do Tocantins, Curso de Zootecnia, Laboratório de Solos, Caixa Postal 132, CEP 77804-970 Araguaína, TO. E-mail: jgsanttos@gmail.com
\end{abstract}

Resumo - O objetivo deste trabalho foi avaliar os efeitos do pré-cultivo de diferentes espécies vegetais e de fungos micorrízicos arbusculares (FMA) na esporulação, colonização e crescimento da braquiária cultivada em sucessão, em casa de vegetação. As plantas cresceram em vasos com uma mistura esterilizada de Latossolo Vermelho distrófico muito argiloso e areia de rio lavada, na proporção de 2:1 (v/v). Inicialmente, foram testados nove tratamentos: seis espécies vegetais micotróficas, uma espécie não micotrófica (nabo-forrageiro), um tratamento com Urochloa decumbens e um controle sem planta. Todos receberam uma mistura de oito espécies de FMA. O delineamento experimental foi inteiramente casualizado, com dez repetições. Foram avaliadas a esporulação e a colonização micorrízica da Urochloa decumbens, a partir de propágulos de FMA remanescentes dos cultivos das seis espécies micotróficas e da espécie não microtrófica. Houve diferença entre as plantas hospedeiras quanto à percentagem de colonização micorrízica e produção total de esporos, tendo sido identificados cinco dos oito isolados estudados. Glomus clarum foi o FMA dominante na maioria dos tratamentos, seguido de Scutellospora heterogama e G. etunicatum. A espécie vegetal em pré-cultivo da braquiária não teve efeito na diversidade de FMA, tendo sido a espécie de fungo o fator efetivo para a composição de isolados fúngicos.

Termos para indexação: colonização, esporulação, micorriza arbuscular, seletividade hospedeira.

\section{Diversity and function of arbuscular mycorrhizal fungi in host species succession}

\begin{abstract}
The objective of this work was to evaluate the effects of pre-cultivation of different plant species and of arbuscular mycorrhizal fungi (AMF) on the sporulation, colonization and growth of Urochloa cultivated in succession, under greenhouse conditions. Plants were grown in pots containing a sterilized mixture of very clayey Oxisol and washed river sand at a 2:1 ratio $(\mathrm{v} / \mathrm{v})$. A completely randomized experiment with nine treatments and ten replicates was initially tested: six mycotrophic plant species; a non-mycotrophic species (forage turnip); a treatment with Urochloa decumbens and a control treatment without plants. All treatments received a mixture of eight AMF species. The mycorrhizal colonization and sporulation of Urochloa decumbens, by means of AMF propagules obtained from the remaining mycotrophic and non-mycotrophic species, was evaluated. There was difference among the host plants in terms of percentage of mycorrhizal colonization and total production of spores, and five out of the eight isolates studied were identified. Glomus clarum was the dominant AMF in most of the treatments, followed by Scutellospora heterogama and G. etunicatum. Pre-cultivation plant species had no effect on the AMF diversity; the fungus species were determinant for the composition of the fungal isolates.
\end{abstract}

Index terms: colonization, sporulation, arbuscular mycorrhiza, host selectivity.

\section{Introdução}

Um importante componente do sistema solo-planta é a microbiota edáfica. Entre os organismos ou grupos funcionais de organismos do solo, os mais intimamente e obrigatoriamente associados ao sistema radicular são os fungos micorrízicos arbusculares (FMA), pertencentes ao filo Glomeromycota, com cerca de 160 espécies identificadas, conforme Invam (2009).

Estudos têm chamado a atenção para a capacidade desses micossimbiontes influenciarem as relações interespecíficas das espécies vegetais na comunidade, como a competição por nutrientes, quando esses recursos são escassos (Heijden et al., 1998; Hartnett \& Wilson,

Pesq. agropec. bras., Brasília, v.44, n.11, p.1483-1490, nov. 2009 
1999; O'Connor et al., 2002), e, com isso, alterar a diversidade e a estrutura de comunidades de plantas.

Vários estudos também têm revelado o caráter funcional dos FMA, a exemplo do trabalho de Heijden et al. (1998), que verificaram que diferentes espécies de FMA influenciaram diferentemente uma determinada comunidade de plantas. Essa resposta diferenciada das hospedeiras à inoculação, com distintas espécies ou isolados de FMA, foi corroborada por estudos como os de Pouyu-Rojas et al. (2006), Santos (2008) e Santos et al. (2008) que, ao trabalhar com várias espécies arbóreas tropicais, demonstraram que esses fungos podem ocupar nichos específicos e proporcionar diferentes serviços para as hospedeiras.

É possível que as comunidades de FMA tenham sua diversidade e estrutura influenciada pelas plantas. Além disso, tem sido demonstrado que há uma pressão de seleção das plantas hospedeiras sobre os fungos, o que indica que podem existir mecanismos bioquímicos específicos de reconhecimento entre os dois que conferem certo grau de especificidade a esse tipo de simbiose (Vandenkoornhuyse et al., 2002, 2003; Scheublin et al., 2004).

De acordo com Brundrett (1991), os esporos são o principal tipo de inóculo, mas muitas vezes a densidade deles não se relaciona com a formação micorrízica nos solos devido à influência de vários outros fatores, inclusive da planta hospedeira e de fatores climáticos e edáficos. As plantas hospedeiras podem diferir muito entre si quanto à capacidade de selecionar os fungos e de afetar a sua multiplicação, o que pode alterar a comunidade de FMA. Carrenho et al. (2002) utilizaram três espécies hospedeiras em estudo da diversidade de FMA em um agroecossistema. Do total de 14 espécies identificadas na área, 7 foram recuperadas das raízes do amendoim, 10 do milho e 12 do sorgo. Verificou-se que enquanto o sorgo favoreceu o estabelecimento de maior número de espécies de FMA, o amendoim estimulou a maior esporulação. Outros fatores que também podem alterar as comunidades de FMA são a micotrofia das plantas e a diversidade de hospedeiras. Johnson et al. (2003) observaram que a diversidade de FMA foi maior em um microssítio, com uma comunidade de plantas hospedeiras, do que em um microssítio de monocultura e que a diversidade ocorreu, também, entre plantas micotróficas e não micotróficas.

Ao comparar as comunidades de FMA que colonizavam as raízes de plantas herbáceas que coexistem naturalmente, Vandenkoornhuyse etal.(2002) verificaram que a comunidade de FMA diferia geneticamente entre as hospedeiras e sofria alterações ao longo do tempo. No entanto, poucos estudos, quase todos de clima temperado, têm sido realizados com esse foco.

Assim, é necessário avançar no entendimento da complexa relação existente entre os parceiros nesse tipo de simbiose, principalmente sob condições tropicais.

O objetivo deste trabalho foi avaliar os efeitos de nove espécies vegetais em isolados de fungos micorrízicos arbusculares e os efeitos do pré-cultivo dessas espécies vegetais no crescimento da Urochloa decumbens e na colonização radicular e esporulação da comunidade fúngica, em sucessão.

\section{Material e Métodos}

Três experimentos foramrealizadosem casadevegetação no Departamento de Ciência do Solo da Universidade Federal de Lavras (DCS-UFLA), entre os meses de abril e setembro de 2006. O primeiro experimento foi para avaliar o efeito do cultivo de diferentes espécies vegetais em isolados de FMA, com 90 dias de duração, e foi conduzido em delineamento inteiramente casualizado com dez repetições. Foram testados nove tratamentos: seis espécies vegetais micotróficas [caupi, Vigna unguiculata (L.) Walp.; amendoim, Arachis hypogaea L.; soja, Glycine max (L.) Merr.; milheto, Pennisetum glaucum (L.) R. Br.; sorgo granífero, Sorghum bicolor (L.) Moench; aveia-preta, Avena strigosa Schreb.], uma espécie não micotrófica [nabo-forrageiro, Raphanus sativus (L.)], um tratamento com Urochloa decumbens (Stapf) R.D. Webster (hospedeiro padrão) e um controle sem planta.

O inóculo utilizado nas espécies vegetais consistiu da mistura de isolados de oito espécies de FMA, provenientes da coleção do Laboratório de Microbiologia do Solo do DCS-UFLA: Glomus etunicatum W. N. Becker \& Gerd. 1977, Glomus clarum T. H. Nicolson \& N. C. Schenck 1979, Gigaspora margarita W. N. Becker \& I. R. Hall 1976, Gigaspora gigantea (T. H. Nicolson \& Gerd) Gerd e Trappe 1974, Scutellospora heterogama (T. H. Nicolson \& Gerd) C. Walker \& F. E. Sanders 1986, Scutellospora pellucida (T. H. Nicolson \& N. C. Schenck) C. Walker \& F. E. Sanders 1986, Acaulospora scrobiculata Trappe 1977 e Entrophospora colombiana Spain \& N.C. Schenck 1984. Amistura continha cerca de 40 esporos viáveis de cada isolado fúngico e foi aplicada ao solo, no momento da semeadura das culturas. Os inóculos foram homogeneizados aos primeiros $3 \mathrm{~cm}$ de profundidade do substrato de plantio. 
As sementes utilizadas foram desinfetadas superficialmente com hipoclorito de sódio, a $1 \%$ por 1 min e colocadas para germinar diretamente nos vasos. As sementes de Urochloa decumbens passaram por um tratamento com ácido sulfúrico concentrado por $1 \mathrm{~min}$, com posterior lavagem em água corrente, para quebra de dormência. Foram plantadas três sementes por vaso e, após a emergência das plântulas, foi efetuado o desbaste, ficando uma planta por vaso.

As plantas cresceram em vasos com capacidade de $1 \mathrm{dm}^{3}$, com mistura de Latossolo Vermelho distrófico (LVd) muito argiloso e areia de rio lavada na proporção de 2:1 (v/v), previamente fumigada com Bromex $(98 \%$ brometo de metila $+2 \%$ cloropicrina) na dosagem de $393 \mathrm{~cm}^{3} \mathrm{~m}^{-3}$, para eliminar os propágulos de FMAs nativos. As características químicas originais do solo foram: $\mathrm{pH}$ 5,$2 ; \mathrm{P}, 1,2 \mathrm{mg} \mathrm{dm}^{-3} ; \mathrm{K}, 17 \mathrm{mg} \mathrm{dm}^{-3} ; \mathrm{Ca}, 0,3 \mathrm{cmol}_{\mathrm{c}} \mathrm{dm}^{-3}$; $\mathrm{Mg}, 0,1 \mathrm{cmol}_{\mathrm{c}} \mathrm{dm}^{-3} ; \mathrm{H}+\mathrm{Al}, 7,9 \mathrm{cmol}_{\mathrm{c}} \mathrm{dm}^{-3}$; matéria orgânica (MO), 4,3 dag $\mathrm{kg}^{-1}$. Foi utilizado calcário dolomítico para elevar a saturação de bases para $60 \%$ (Raij, 1981), e foram adicionados $52 \mathrm{mg} \mathrm{dm}^{-3}$ de P na forma de superfosfato triplo, para obter $0,02 \mathrm{mg} \mathrm{kg}^{-1} \mathrm{de}$ P na solução do solo (Habte \& Manjunath, 1991).

Após 15 dias da emergência, as plântulas receberam solução nutritiva de Hoagland sem $\mathrm{P}$ a $50 \%$ da concentração original (Hoagland \& Arnon, 1950) em intervalos de 15 dias. A irrigação foi realizada de modo a manter a umidade do substrato com $60 \%$ do volume total de poros ocupados com água. Noventa dias após a germinação, as plantas foram retiradas dos vasos e as partes aéreas e raízes, separadas. Foram coletados aproximadamente $50 \mathrm{~mL}$ de substrato, após homogeneização, para extração dos esporos pelo método de peneiramento úmido (Gerdemann \& Nicolson, 1963), seguido de centrifugação com solução de sacarose $\left(500 \mathrm{~g} \mathrm{~L}^{-1}\right)$. As raízes foram lavadas em água abundante até a completa eliminação das partículas de solo e de outras fontes externas de propágulos micorrízicos. Cerca de $1 \mathrm{~g}$ das raízes frescas foi utilizado na avaliação da taxa de colonização micorrízica, após coloração segundo Phillips \& Hayman (1970) e contagem segundo Giovannetti \& Mosse (1980).

O segundo experimento foi realizado sobre o mesmo substrato do primeiro experimento para verificar o efeito do pré-cultivo para a cultura em sucessão. A braquiária foi utilizada como planta hospedeira, e teve como inóculo os propágulos micorrízicos remanescentes dos cultivos do primeiro experimento. Após 180 dias da germinação da braquiária, as plantas foram colhidas e a massa de matéria seca da parte aérea e raízes, o número de esporos e a taxa de colonização micorrízica foram determinados.

Para o terceiro experimento, com objetivo de avaliar o efeito seletivo das diferentes espécies vegetais nos isolados de FMA utilizados inicialmente, foram retirados cerca de $4 \mathrm{~g}$ de raízes frescas das espécies vegetais cultivadas no primeiro experimento. Essa foi a única fonte de inóculo para a Urochloa decumbens, utilizada como hospedeiro em todos os tratamentos. $\mathrm{O}$ experimento foi realizado com dez repetições e um tratamento controle não inoculado.

Após 180 dias, as plantas de braquiária foram colhidas e foram separadas as partes aérea e raízes, a partir das quais foi determinada a massa de matéria seca após secagem em estufa com circulação de ar a $60^{\circ} \mathrm{C}$ até massa constante. Também foi avaliado o número de esporos e determinada a taxa de colonização micorrízica.

Todos os dados foram submetidos à análise de variância e ao teste de média pelo Scott-Knott, a 5\% de probabilidade pelo SISVAR (Ferreira, 2000), e os resultados de colonização micorrízica foram transformados pelo arc sen $(\mathrm{x} / 100)^{0,5}$.

\section{Resultados e Discussão}

No primeiro experimento, a percentagem de colonização micorrízica e esporulação dos FMAs variou com a espécie vegetal (Tabela 1). Apesar de o nabo-forrageiro ser não micotrófico, foi verificado um nível de colonização de $1,8 \%$ nas raízes, o que é considerado muito baixo, sem formação das estruturas típicas do estabelecimento da simbiose, como os arbúsculos, e sem esporulação.

Land et al. (1993) verificaram que a frequência de infecção micorrízica e a dinâmica de esporos no solo diferem com a espécie de planta, com o aumento na área com culturas onde há histórico com plantas hospedeiras (trigo e cevada) e com a redução nas áreas cultivadas com espécie não hospedeira (beterraba).

Entre as espécies micotróficas, a colonização micorrízica foi elevada e variou de 40 (sorgo) até 70\% (aveia-preta) (Tabela 1). A colonização na aveia-preta não foi superior apenas à verificada no amendoim e na soja. Entre caupi, milheto e braquiária, não houve 
diferença significativa na colonização, que foi superior a $50 \%$, o que demonstra a compatibilidade dos FMA com as espécies hospedeiras testadas.

A produção total de esporos variou muito entre tratamentos (Tabela 1). Nos tratamentos sem planta e nabo-forrageiro, foi verificado apenas um esporo por $50 \mathrm{~mL}$ de solo; nos demais tratamentos, a esporulação foi abundante e variou de 113 esporos na aveia-preta a 1.058 no amendoim. Com exceção dos tratamentos sem planta e nabo-forrageiro, em média, mais de $95 \%$ dos esporos foram de G. clarum.

Todos os tratamentos apresentaram baixas quantidades de esporos de $S$. heterogama. Os demais isolados apresentaram no máximo dois esporos, independentemente das plantas testadas. Houve efeito seletivo das espécies vegetais, com um dos oito isolados inicialmente inoculados dominando a produção de esporos. Entre as espécies vegetais estudadas, a braquiária foi a menos seletiva, com cinco dos oito isolados produzindo esporos. Não houve correlação entre a taxa de colonização micorrízica e a esporulação dos FMA ( $\mathrm{p}>0,05)$.

Tanto a colonização radicular da Urochloa decumbens quanto a produção de esporos variaram com os tratamentos de pré-cultivo (Tabela 2). A colonização micorrízica variou de 23 a $41 \%$, com os maiores valores encontrados em sucessão ao caupi, aveia-preta e nabo-forrageiro. A colonização da braquiária neste experimento foi de $31 \%$, inferior à observada no primeiro experimento $(51 \%)$.

O maior potencial de inóculo (número total de esporos) nos tratamentos de pré-cultivo com plantas

Tabela 1. Colonização micorrízica (\%) das espécies vegetais estudadas em pré-cultivo da Urochloa decumbens e esporulação (número de esporos por $50 \mathrm{~mL}$ de solo) dos isolados de $\mathrm{FMA}^{(1)}$.

\begin{tabular}{|c|c|c|c|c|c|c|c|c|c|c|}
\hline \multirow[t]{2}{*}{ Hospedeiras } & \multirow[t]{2}{*}{ Colonização } & \multicolumn{9}{|c|}{ Esporulação } \\
\hline & & G.cla & S.het & Gi.mar & G.etu & E.col & Gi.gig & S.pel & A.scr & Total \\
\hline Amendoim & $64 a$ & 1.054 & 4 & 0 & 0 & 0 & 0 & 0 & 0 & $1.058 \mathrm{a}$ \\
\hline Caupi & $56 b$ & 387 & 5 & 1 & 0 & 0 & 0 & 0 & 0 & $393 c$ \\
\hline Soja & $61 \mathrm{a}$ & 291 & 1 & 0 & 0 & 0 & 0 & 0 & 0 & $292 d$ \\
\hline Aveia-preta & $70 \mathrm{a}$ & 109 & 4 & 0 & 0 & 0 & 0 & 0 & 0 & $113 \mathrm{f}$ \\
\hline Braquiária & $51 \mathrm{~b}$ & 169 & 7 & 1 & 2 & 1 & 0 & 0 & 0 & $180 \mathrm{e}$ \\
\hline Milheto & $54 \mathrm{~b}$ & 758 & 7 & 0 & 0 & 0 & 0 & 0 & 0 & $765 b$ \\
\hline Sorgo & $40 c$ & 254 & 5 & 2 & 0 & 0 & 0 & 0 & 0 & $261 d$ \\
\hline Nabo-forrageiro & $2 d$ & 0 & 1 & 0 & 0 & 0 & 0 & 0 & 0 & $1 \mathrm{~g}$ \\
\hline Sem planta & - & 0 & 1 & 0 & 0 & 0 & 0 & 0 & 0 & $1 \mathrm{~g}$ \\
\hline $\mathrm{CV}(\%)$ & 7,80 & & & & & & & & & 17,42 \\
\hline
\end{tabular}

${ }^{(1)}$ Médias seguidas por letras iguais na coluna não diferem pelo teste de Scott-Knott, a 5\% de probabilidade. G.cla, Glomus clarum; G.etu, Glomus etunicatum; S.het, Scutellospora heterogama; S.pel, Scutellospora pellucida; Gi.gig, Gigaspora gigantea; Gi.mar, Gigaspora margarita; A.scr, Acaullospora scrobiculata; E.col., Entrophospora colombiana.

Tabela 2. Colonização micorrízica (\%) de Urochloa decumbens, cultivada em sucessão a oito espécies e um tratamento sem planta, e esporulação (número de esporos por $50 \mathrm{~mL}$ de solo) dos isolados de $\mathrm{FMA}^{(1)}$.

\begin{tabular}{|c|c|c|c|c|c|c|c|c|c|c|}
\hline \multirow[t]{2}{*}{ Pré-cultivo } & \multirow[t]{2}{*}{ Colonização } & \multicolumn{9}{|c|}{ Esporulação } \\
\hline & & G.cla & S.het & Gi.mar & G.etu & E.col & Gi.gig & S.pel & A.scr & Total \\
\hline Amendoim & $31 \mathrm{~b}$ & $87 d$ & $87 a$ & 2 & 4 & 0 & $6 a$ & 0 & 0 & $186 \mathrm{~b}$ \\
\hline Caupi & $41 \mathrm{a}$ & $187 \mathrm{c}$ & $30 \mathrm{~b}$ & 2 & 7 & 0 & $2 b$ & 0 & 0 & $228 b$ \\
\hline Soja & $27 b$ & $451 \mathrm{a}$ & $70 \mathrm{a}$ & 4 & 3 & 0 & $2 b$ & 0 & 0 & $530 \mathrm{a}$ \\
\hline Aveia-preta & $36 a$ & $31 d$ & $22 b$ & 1 & 22 & 0 & $0 \mathrm{c}$ & 0 & 0 & $76 c$ \\
\hline Braquiária & $31 b$ & $83 d$ & $45 b$ & 2 & 6 & 0 & $2 b$ & 0 & 0 & $138 \mathrm{c}$ \\
\hline Milheto & $23 b$ & $84 d$ & $31 b$ & 0 & 0 & 0 & $0 \mathrm{c}$ & 0 & 0 & $115 c$ \\
\hline Sorgo & $30 \mathrm{~b}$ & $73 d$ & $40 \mathrm{~b}$ & 0 & 8 & 0 & $1 \mathrm{c}$ & 0 & 0 & $122 \mathrm{c}$ \\
\hline Nabo-forrageiro & $34 \mathrm{a}$ & $66 \mathrm{~d}$ & $61 \mathrm{a}$ & 2 & 9 & 0 & $1 \mathrm{c}$ & 0 & 0 & $139 c$ \\
\hline Sem planta & $28 b$ & $263 b$ & $7 \mathrm{~b}$ & 1 & 5 & 0 & $0 \mathrm{c}$ & 0 & 0 & $276 \mathrm{~b}$ \\
\hline $\mathrm{CV}(\%)$ & 7,56 & & & & & & & & & 46,81 \\
\hline
\end{tabular}

${ }^{(1)}$ Médias seguidas por letras iguais na coluna não diferem pelo teste de Scott-Knott, a 5\% de probabilidade. G.cla, Glomus clarum; G.etu, Glomus etunicatum; S.het, Scutellospora heterogama; S.pel, Scutellospora pellucida; Gi.gig, Gigaspora gigantea; Gi.mar, Gigaspora margarita; A.scr, Acaullospora scrobiculata; E.col, Entrophospora colombiana. 
micotróficas não influenciou a taxa de colonização da braquiária em sucessão em relação aos tratamentos com nabo-forrageiro e controle, o que está de acordo com a correlação não significativa observada entre essas variáveis $(p>0,05)$. Isso evidencia maior efeito da espécie hospedeira do que da cultura anterior no potencial de inóculo do solo para influenciar a colonização radicular.

A produção total de esporos, após o pré-cultivo, variou de 530 a 76 esporos por $50 \mathrm{~mL}$ de solo em soja e aveia-preta, respectivamente (Tabela 2). Esta última não diferiu dos tratamentos com milheto, sorgo, braquiária e nabo-forrageiro e foi inferior às produções sem planta e de caupi, amendoim e soja. Deve-se destacar o tratamento de pré-cultivo com soja, que praticamente dobrou a produção de esporos em relação ao tratamento sem planta, no qual se observou a segunda maior quantidade de esporos (cerca de 276). Tanto G. clarum como $S$. heterogama foram encontrados em todos os tratamentos em que a contribuição de G. clarum para a esporulação total foi menor em relação ao experimento anterior, tendo aumentado principalmente a contribuição de $S$. heterogama. Isso foi bem evidente no pré-cultivo com amendoim e nabo-forrageiro, entre os quais praticamente não houve diferença. Os demais isolados tiveram pouca participação na esporulação total, exceto $G$. etunicatum que, no tratamento com aveia-preta, produziu esporos em quantidades semelhantes às de G. clarum e S. heterogama. Não foram

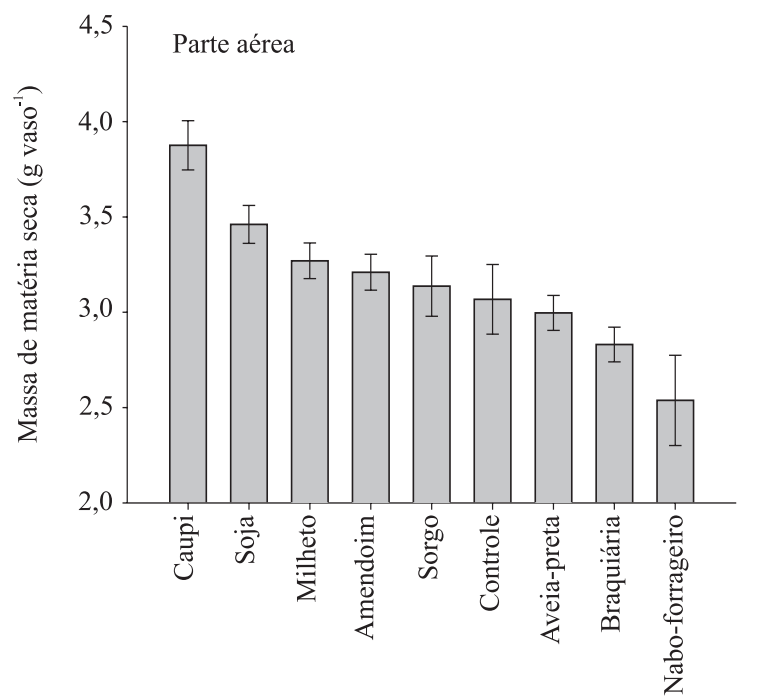

encontrados esporos de E. colombiana, S. pellucida ou A. scrobiculata em nenhum dos tratamentos.

No terceiro experimento, houve efeito significativo dos tratamentos para a produção da massa de matéria seca da braquiária (Figura 1 A e B) e produção de esporos (Tabela 3). A massa de matéria seca da parte aérea (MSPA) variou de 3,8 a 2,6 g por planta nos tratamentos com raízes de caupi colonizadas e com raízes de nabo-forrageiro, respectivamente, o que representou um incremento de $32 \%$ devido ao inóculo com raízes de caupi.

Apenas três dos oito tratamentos testados diferiram do controle (sem inoculação micorrízica), tendo o caupi e a soja aumentado a MSPA da braquiária em relação ao controle (Figura $1 \mathrm{~A}$ ). O tratamento com caupi foi superior ao com soja, que foi superior aos demais. A maioria dos tratamentos aumentou a produção de massa de matéria seca de raízes em relação ao não inoculado, com exceção de soja, amendoim e nabo-forrageiro (Figura $1 \mathrm{~B}$ ). Em nenhum tratamento foi observada redução da massa de matéria seca da raiz em relação ao não inoculado. A soja, que incrementou a MSPA, não apresentou qualquer efeito na massa de matéria seca de raiz.

A percentagem de colonização micorrízica da braquiária variou apenas quando foram comparados os tratamentos com inóculos de FMA e sem inóculos. Nesse último, não foi encontrado nenhum vestígio de colonização (Tabela 3). O valor médio de colonização radicular nos tratamentos com inóculos foi de $28 \%$.

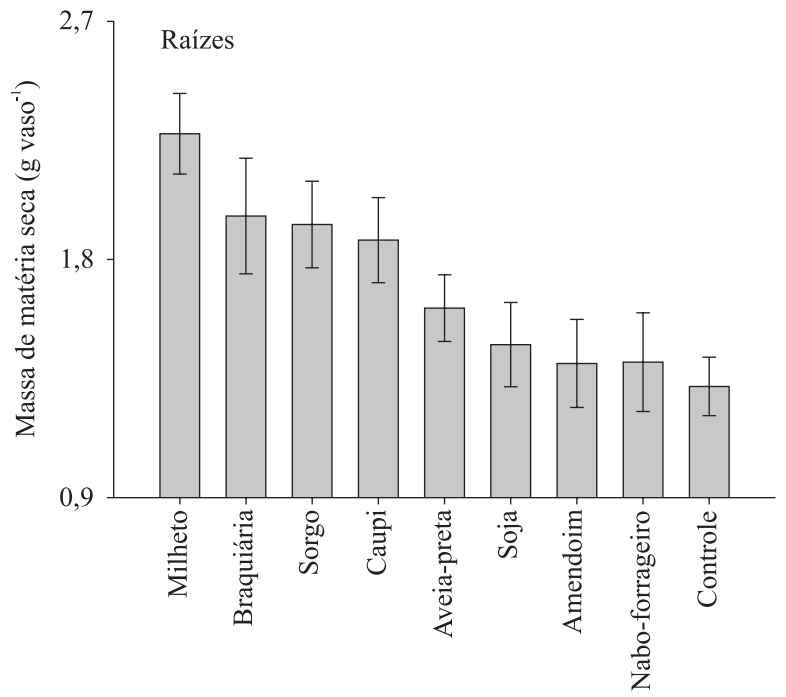

Figura 1. Massa de matéria seca da parte aérea e raiz de Urochloa decumbens com inóculo oriundo de raízes de oito espécies vegetais, mais o controle sem inóculo. Barras representam o erro-padrão. 
Diferentemente da colonização radicular, observouse efeito dos tratamentos para esporulação. Não foi encontrado nenhum esporo no tratamento sem inóculo. Nos tratamentos com inóculos, o número de esporos variou de 25 (nabo-forrageiro) a 274 (milheto). A maior esporulação no tratamento com raízes colonizadas por FMA foi encontrada em milheto, seguida de sorgo e aveia-preta, com média de 255 esporos por $50 \mathrm{~mL}^{-1}$ de solo; a menor foi encontrada em nabo-forrageiro, seguida de amendoim e braquiária, com média de 46 esporos por $50 \mathrm{~mL}^{-1}$. A quase totalidade dos esporos pertence ao isolado Glomus clarum. Outros dois isolados também foram identificados ao final do experimento, quando foram encontrados um esporo de Gigaspora margarita e sete de Glomus etunicatum.

A variação na colonização micorrízica verificada entre os tratamentos do primeiro experimento demonstra a forte influência da planta, pois houve dominância de um dos oito isolados inicialmente inoculados, com mais de 95\% do total de esporos; portanto, é esperado que esse isolado tenha dominado também a colonização. Esse mecanismo de controle da colonização micorrízica foi demonstrado por Pouyu-Rojas et al. (2006) que, ao estudar a combinação entre 16 espécies arbóreas nativas em fase juvenil e dez tratamentos com FMA, observaram que a colonização micorrízica variou muito entre as espécies vegetais para um único isolado fúngico e também entre os isolados de FMA para uma mesma planta. Esses dados apoiam o presente estudo em relação aos tratamentos com braquiária como único hospedeiro, mas com diferenças entre os tratamentos quanto aos inóculos fúngicos.
No segundo experimento, apesar de haver variação entre os tratamentos quanto à colonização, ela foi pequena, enquanto a colonização da braquiária não variou.

No terceiro experimento, não foi verificada diferença quanto à colonização entre os tratamentos com inóculos. Esperava-se que tratamentos como o da aveia-preta, com $70 \%$ de colonização, e o do nabo-forrageiro, com menos de $2 \%$, influenciassem a colonização da braquiária.

Quanto à influência dos diferentes tratamentos nas populações de FMA avaliadas com base na esporulação dos fungos, verificou-se que, no primeiro experimento, a esporulação variou com os tratamentos, com destaque para as espécies hospedeiras e para os isolados de FMA. Carrenho et al. (2002), que estudaram o efeito de diferentes plantas hospedeiras na diversidade de FMA, observaram que o amendoim estimulou a esporulação em relação ao sorgo e ao milho, enquanto o sorgo foi superior no estabelecimento de maior número de espécies dos fungos. Mergulhão et al. (2009), ao avaliar a influência de diferentes plantas hospedeiras e de ciclos de multiplicação em cultura-armadilha na ocorrência e diversidade de FMA no Semiárido, observaram que o amendoim apresentou maiores valores de colonização radicular, enquanto no sorgo houve maior número de esporos no segundo e no terceiro ciclo da cultura-armadilha. No presente estudo, foi verificado comportamento semelhante em relação à esporulação e ao número de espécies de fungos. A influência do isolado fúngico na esporulação total foi pequena entre as diversas

Tabela 3. Colonização micorrízica (\%) de Urochloa decumbens por propágulos micorrízicos contidos nas raízes de oito espécies vegetais e esporulação dos inóculos de FMA (número de esporos por $50 \mathrm{~mL}$ de solo) ${ }^{(1)}$.

\begin{tabular}{|c|c|c|c|c|c|c|c|c|c|c|}
\hline \multirow[t]{2}{*}{ Fonte de inóculo } & \multirow[t]{2}{*}{ Colonização } & \multicolumn{9}{|c|}{ Esporulação } \\
\hline & & G.cla & S.het & Gi.mar & G.etu & E.col & Gi.gig & S.pel & A.scr & Total \\
\hline Amendoim & $22 \mathrm{a}$ & $52 b$ & 0 & 0 & 0 & 0 & 0 & 0 & 0 & $52 \mathrm{c}$ \\
\hline Caupi & $32 \mathrm{a}$ & $200 \mathrm{a}$ & 0 & 0 & 0 & 0 & 0 & 0 & 0 & $200 \mathrm{~b}$ \\
\hline Soja & $31 \mathrm{a}$ & $148 b$ & 0 & 0 & 0 & 0 & 0 & 0 & 0 & $148 b$ \\
\hline Aveia-preta & $30 \mathrm{a}$ & $234 a$ & 0 & 0 & 3 & 0 & 0 & 0 & 0 & $237 \mathrm{a}$ \\
\hline Braquiária & $28 \mathrm{a}$ & $63 b$ & 0 & 0 & 0 & 0 & 0 & 0 & 0 & $63 c$ \\
\hline Milheto & $29 \mathrm{a}$ & $271 \mathrm{a}$ & 0 & 1 & 2 & 0 & 0 & 0 & 0 & $274 a$ \\
\hline Sorgo & $27 \mathrm{a}$ & $253 a$ & 0 & 0 & 2 & 0 & 0 & 0 & 0 & $255 \mathrm{a}$ \\
\hline Nabo-forrageiro & $22 \mathrm{a}$ & $25 b$ & 0 & 0 & 0 & 0 & 0 & 0 & 0 & $25 \mathrm{c}$ \\
\hline Controle & $0 \mathrm{~b}$ & $0 \mathrm{~b}$ & 0 & 0 & 0 & 0 & 0 & 0 & 0 & $0 \mathrm{c}$ \\
\hline CV (\%) & 15,55 & & & & & & & & & 48,55 \\
\hline
\end{tabular}

(1) Médias seguidas por letras iguais na coluna não diferem pelo teste de Scott-Knott, a 5\% de probabilidade. G.cla, Glomus clarum; G.etu, Glomus etunicatum; S.het, Scutellospora heterogama; S.pel, Scutellospora pellucida; Gi.gig, Gigaspora gigantea; Gi.mar, Gigaspora margarita; A.scr, Acaullospora scrobiculata; E.col, Entrophospora colombiana. 
hospedeiras, em que $95 \%$ da esporulação foi atribuída a G. clarum. Isso demonstra que houve maior efeito da planta sobre essa variável, o que é reforçado pela menor amplitude de esporulação entre os tratamentos no segundo e terceiro experimento, que tiveram como único hospedeiro a braquiária. $\mathrm{O}$ isolado G. clarum mostrou-se mais competitivo em termos de quantidade de esporos produzidos, e dominou a comunidade de fungos, independentemente dos tratamentos, principalmente no primeiro e terceiro experimento. Esse resultado pode estar relacionado ao caráter generalista quanto ao hospedeiro e à ampla eficiência demonstrada por esse isolado em estudo de Pouyu-Rojas et al. (2006). Enquanto alguns FMA colonizam rapidamente o hospedeiro e produzem abundante esporulação, outros necessitam de mais tempo para esporular ou esporulam pouco e persistem no ambiente, principalmente na forma ativa, e não como esporo. Esse resultado reforça o conceito de variação da comunidade de FMA que foi estudado por Husband et al. (2002).

Entre os fatores que influenciam a composição e a diversidade de uma comunidade de FMA, como variação espacial, idade, tipo de hospedeiro e tempo, outro fator não menos importante é a estratégia de vida da espécie ou isolado fúngico. Dos fatores que interferem na estrutura e diversidade de uma comunidade de FMA, o tempo teve forte influência neste trabalho, assim como a estratégia de sobrevivência dos isolados. Isso é bem evidenciado ao comparar os dados de esporulação do primeiro experimento (conduzido por 90 dias) com o segundo experimento (conduzido por 180 dias). Apesar de o número de isolados fúngicos identificados não ter variado, verificou-se que, aos 180 dias, houve uma contribuição mais equilibrada entre os isolados estudados para esporulação total. Enquanto no primeiro experimento o $G$. clarum dominou a esporulação, no segundo experimento, a participação desse fungo caiu consideravelmente em todos os tratamentos. No segundo experimento, G. clarum e $S$. heterogama apresentaram quantidades semelhantes de esporos. Os demais isolados contribuíram mais para a esporulação total. O efeito da seletividade da planta na estrutura e na diversidade de uma determinada comunidade de FMA pode ser modulado pela espécie de fungo e pelo tempo, o que interfere nos resultados.

\section{Conclusões}

1. A espécie hospedeira não tem efeito na diversidade de isolados de FMA em sucessão, mas a espécie de FMA é o fator efetivo para a composição de isolados.

2. As espécies hospedeiras em pré-cultivo influenciam a colonização micorrízica, a produção de esporos e afetam o crescimento da Urochloa decumbens cultivada em sucessão.

3. A composição de isolados de FMA é influenciada pelo pré-cultivo com predomínio de Glomus clarum; porém, o cultivo com Urochloa decumbens em sucessão favorece a ocorrência de outros isolados fúngicos.

\section{Referências}

BRUNDRETT, M. Mycorrhizas in natural ecosystems. Advances in Ecological Research, v.21, p.171-313, 1991.

CARRENHO, R.; TRUFEM, S.F.B.; BONONI, V.L.R. Effects of using different host plants on the detected biodiversity of arbuscular mycorrhizal fungi from an agroecosystem. Revista Brasileira Botânica, v.25, p.93-101, 2002.

FERREIRA, D.F. Análises estatísticas por meio do SISVAR para Windows. Versão 4.0. Lavras: Ufla, 2000. 63p.

GERDEMANN, J.W.; NICOLSON, T.H. Spores of mycorrhizal Endogone species extracted from soil wet sieving and decanting. Transactions of British Mycological Society, v.46, p.235-244, 1963.

GIOVANNETTI, M.; MOSSE, B. An evaluation of techniques for measuring vesicular arbuscular mycorrhizal infection in roots. New Phytologist, v.84, p.489-500, 1980.

HABTE, M.; MANJUNATH, A. Categories of vesicular arbuscular mycorrhizal dependency of host species. Mycorrhiza, v.1, p.3-12, 1991.

HARTNETT, D.C.; WILSON, G.W.T. Mycorrhizae influence plant community structure and diversity in tallgrass prairie. Ecology, v.80, p.1187-1195, 1999.

HEIJDEN, M.G.A. van der; BOLLER, T.; WIEMKEN, A.; SANDERS, I.R. Different arbuscular mycorrhizal fungal species are potential determinants of plant community structure. Ecology, v.79, p.2082-2091, 1998.

HOAGLAND, D.R.; ARNON, D.I. The water culture method of growing plants without soil. Berkeley: University of California, 1950. 32p.

HUSBAND, R.; HERRE, E.A.; TURNER, S.L.; GALLERY, R.; YOUNG, J.P.W. Molecular diversity of arbuscular mycorrhizal fungi and patterns of host association over time and space in a tropical forest. Molecular Ecology, v.11, p.2669-2678, 2002.

INVAM. International culture collection of (vesicular) arbuscular mycorrhizal fungi. Disponível em: <http://invam.caf. wvu.edu/>. Acesso em: 16 dez. 2009.

JOHNSON, D.; VANDENKOORNHUYSE, P.J.; LEAKE, J.R.; GILBERT, L.; BOOTH, R.E.; GRIME, P.; YOUNG, J.P.W.; READ, 
D.J. Plant communities affect arbuscular mycorrhizal fungal diversity and community composition in grassland microcosms. New Phytologist, v.161, p.503-505, 2003.

LAND, S.; ALTEN, H. von; SCHÖNBECK, F. The influence of host plant, nitrogen fertilization and fungicide application on the abundance and seasonal dynamics of vesicular-arbuscular mycorrhizal fungi in arable soils of northern Germany. Mycorrhiza, v.2, p.157-166, 1993.

MERGULHÃO, A.C. do E.S.; FIGUEIREDO, M. do V.B.; BURITY, H.A.; MAIA, L.C. Hospedeiros e ciclos sucessivos de multiplicação afetam a detecção de fungos micorrízicos arbusculares em áreas impactadas por mineração gesseira. Revista Árvore, v.33, p.227-236, 2009.

O'CONNOR, P.J.; SMITH, S.E.; SMITH, F.A. Arbuscular mycorrhizas influence plant diversity and community structure in a semiarid herbland. New Phytologist, v.154, p.209-218, 2002.

PHILLIPS, J.M.; HAYMAN, D.S. Improved procedures for clearing roots and staining parasitic and vesicular-arbuscular mycorrizal fungi for rapid assessment of infection. Transactions of the British Mycologycal Society, v.55, p.158-161, 1970.

POUYU-ROJAS, E.; SIQUEIRA, J.O.; SANTOS, J.G.D. Compatibilidade simbiótica de fungos micorrízicos arbusculares com espécies arbóreas tropicais. Revista Brasileira de Ciência do Solo, v.30, p.413-424, 2006.
RAIJ, B. van. Avaliação da fertilidade do solo. Piracicaba: POTAFOS, 1981. 142p.

SANTOS, J.G.D. Riqueza de fungos micorrízicos arbusculares no solo e o crescimento inicial de espécies arbóreas nativas. 2008. 80p. Tese (Doutorado) - Universidade Federal de Lavras, Lavras.

SANTOS, J.G.D.; SIQUEIRA, J.O.; MOREIRA, F.M. de S. Eficiência de fungos micorrízicos arbusculares isolados de solos de áreas de mineração de bauxita no crescimento inicial de espécies nativas.

Revista Brasileira de Ciência do Solo, v.32, p.141-150, 2008.

SCHEUBLIN, T.R.; RIDGWAY, K.P.; YOUNG, J.P.W.; HEIJDEN, M.G.A. van der. Nonlegumes, legumes, and root nodules harbor different arbuscular mycorrhizal fungal communities. Applied and Environmental Microbiology, v.70, p.6240-6246, 2004.

VANDENKOORNHUYSE, P.; HUSBAND, R.; DANIELL, T.J.; WATSON, I.J.; DUCK, J.M.; FITTER, A.H.; YOUNG, J.P.W. Arbuscular mycorrhizal community composition associated with two plant species in a grassland ecosystem. Molecular Ecology, v.11, p.1555-1564, 2002.

VANDENKOORNHUYSE, P.; RIDGWAY, K.P.; WATSON, I.J.; FITTER, A.H.; YOUNG, J.P.W. Co-existing grass species have distinctive arbuscular mycorrhizal communities. Molecular Ecology, v.12, p.3085-3095, 2003.

Recebido em 24 de abril de 2009 e aprovado em 27 de outubro de 2009 